\title{
CDK 4/6 Inhibitors as Single Agent in Advanced Solid Tumors
}

\section{OPEN ACCESS}

Edited by:

Yunkai Zhang

Vanderbilt University Medical Center,

United States

Reviewed by:

Mao Wang,

Memorial Sloan Kettering Cancer

Center, United States

Zhenfang Du,

Vanderbilt University Medical Center,

United States

Junyi Li,

University of Pittsburgh, United States

*Correspondence:

Francesco Schettini

francescoschettini1987@gmail.com

tThese authors have contributed equally to this work

¥These authors share co-last authorship

Specialty section:

This article was submitted to

Cancer Molecular Targets and

Therapeutics,

a section of the journal

Frontiers in Oncology

Received: 26 October 2018 Accepted: 28 November 2018 Published: 12 December 2018

Citation:

Schettini F, De Santo I, Rea CG,

De Placido P, Formisano L,

Giuliano M, Arpino G, De Laurentiis M,

Puglisi F, De Placido $S$ and

Del Mastro L (2018) CDK 4/6

Inhibitors as Single Agent in Advanced

Solid Tumors. Front. Oncol. 8:608.

doi: 10.3389/fonc.2018.00608

\begin{abstract}
Francesco Schettini ${ }^{1 \star t}$, Irene De Santo ${ }^{1 \dagger}$, Carmen G. Rea ${ }^{1}$, Pietro De Placido ${ }^{1}$ Luigi Formisano $^{1}$, Mario Giuliano ${ }^{1,2}$, Grazia Arpino ${ }^{1}$, Michelino De Laurentiis ${ }^{3}$, Fabio Puglisi ${ }^{4,5}$, Sabino De Placido ${ }^{1 \neq}$ and Lucia Del Mastro ${ }^{6,7 \neq}$
\end{abstract}

${ }^{1}$ University of Naples Federico II, Naples, Italy, ${ }^{2}$ Baylor College of Medicine, Houston, TX, United States, ${ }^{3}$ Istituto Nazionale Tumori Fondazione G. Pascale, Naples, Italy, ${ }^{4}$ Department of Medicine, University of Udine, Udine, Italy, ${ }^{5}$ IRCCS Centro di Riferimento Oncologico Aviano, Aviano, Italy, ${ }^{6}$ Policlinico San Martino-IST, Genova, Italy, ${ }^{7}$ University of Genova, Genova, Italy

Cyclin-dependent kinases (CDK) 4/6 inhibitors, namely abemaciclib, palbociclib, and ribociclib, interfere with cell cycle progression, induce cell senescence and might promote cancer cell disruption by a cytotoxic T cells-mediated effect. Phase III randomized clinical trials have proven that CDK4/6 inhibitors (CDK4/6i) in combination with several endocrine agents improve treatment efficacy over endocrine agents alone for hormone receptor positive (HR+) HER2 negative (HER2-) metastatic breast cancer (MBC). Based on such results, these combinations have been approved for clinical use. Preclinical studies in cell cultures and mouse models proved that CDK4/6i are active against a broad spectrum of solid tumors other than breast cancer, including liposarcoma, rhabdomyosarcoma, non-small cell lung cancer, glioblastoma multiforme, esophageal cancer, and melanoma. The role of CDK4/6i in monotherapy in several solid tumors is currently under evaluation in phase I, II, and III trials. Nowadays, abemaciclib is the only of the three inhibitors that has received approval as single agent therapy for pretreated HR+ HER2- MBC. Here we review biological, preclinical and clinical data on the role of CDK4/6 inhibitors as single agents in advanced solid tumors.

Keywords: solid tumors, cyclin-dependent kinases, palbociclib, ribociclib, abemaciclib, cell cycle

\section{INTRODUCTION}

The key role of cyclin-dependent kinases (CDK) and D-type Cyclins (CCND) in cell cycle progression from G1 to $S$ phase was discovered more than 20 years ago (1). Since then, it has been demonstrated that several solid tumors present direct modifications of genes codifying for several proteins involved in CCND-CDK activity and regulation (2). As a result, in recent years, small molecule inhibitors which target this mitogenic pathway have been developed. Three of them are currently available for the treatment of metastatic breast cancer (MBC) in combination with aromatase inhibitors or fulvestrant. This review focuses on the role of CCND-CDK in normal cells, on how this pathway is altered in solid tumors and on the activity of CDK4/6 inhibitors (CDK4/6i), as single agents in the treatment of advanced solid tumors in adult patients. 


\section{THE ROLE OF CDK IN CELL CYCLE AND SOLID TUMORS}

CCND interact with several CDK, including CDK 4/6, forming functional complexes that phosphorylate and inactivate retinoblastoma protein $(\mathrm{pRb})(1)$. This protein operates a negative control on E2F transcription factors, resulting in an inhibition of cell cycle progression. Indeed, E2F modulates the expression of a broad variety of genes implied in cell cycle S1 phase and mitosis. On the opposite, functional CCND-CDK4/6 complexes allow E2F to be released from $\mathrm{pRb}$ control and promote the transition from the G1 to the $S$ phase of the cell cycle (Figure 1) (1). Cyclin D is important in growth factor signaling and, more in general, is a common downstream pathway for several mitogenic signaling, including phosphatidylinositol 3-kinase (PI3K)/AKT/mammalian target of rapamycin (mTOR), mitogen-activated protein kinase (MAPK), wnt/beta-catenin, janus kinase (JAK)-signal transducer and activator of transcription (STAT), nuclear factor kappalight-chain-enhancer of activated B cells (NF-kB), and steroid hormone signaling pathways (e.g., estrogen, progesterone, and androgen) (Figure 1) (2). CDK $4 / 6$ activity is regulated by the INK4 family of proteins. Among them, $16^{\text {INK4A }}$ appears to be the most relevant, in terms of tumor suppression activity. Several other factors, including $\mathrm{p} 21^{\mathrm{CIP} 1}$ and $\mathrm{p} 27^{\mathrm{KIP} 1}$ modulate CCNDCDK4/6 complexes' activity in a context-dependent manner (2). Finally, the SMARCB1/INI1/SNF5 tumor suppressor gene directly represses the transcription of the Cyclin-D coding gene CCND1 and increases the expression of CCND-CDK4/6 negative regulators $\mathrm{p} 16^{\mathrm{INK} 4 \mathrm{~A}}$ and $\mathrm{p} 21^{\mathrm{CIP} 1}$ (2).

In solid tumors, an hyperactivation of the CCND-CDK4/6 activity can occur through: (1) increased activity of upstream mitogenic signaling pathways; (2) aberrant activity of the components of the pathway or their regulators. This latter may depend on various molecular mechanisms, i.e., point mutations, translocations or amplification of CDK4/6, amplification of D-type cyclins, deletions that cause the loss of $\mathrm{p} 16^{\mathrm{INK} 4 \mathrm{~A}}$ or $\mathrm{pRb}$ expression, epigenetic modifications and downregulation of microRNAs (miRNAs) that target CDK4/6. Alterations of the expression of CCND-CDK4/6-INK4-Rb pathway components or of their direct regulators result in cell cycle progression and cell

Abbreviations: CDK4/6, cyclin-dependent kynases 4 and 6; CDK4/6i, CDK4/6 inhibitors; CCND, cyclin D; PI3K, phosphatidylinositol 3-kinase; mTOR, mammalian target of rapamycin; MAPK, mitogen-activated protein kinase; JAK, janus kinase; STAT, signal transducer and activator of transcription; NF-kB, nuclear factor kappa-light-chain-enhancer of activated B cells; miRNAs, microRNAs; pRb, retinoblastoma protein; ET, endocrine therapy; $\mathrm{ER}+$, estrogen receptor positive; HR+, hormone receptor positive; HER2-, human epidermal growth factor receptor 2 negative; $\mathrm{MBC}$, metastatic breast cancer; BC, breast cancer; GBM, glioblastoma multiforme; WD/DDLS, welldifferentiated/dedifferentiated liposarcoma; NSCLC, non-small cell lung cancer; SCLC, small cell lung cancer; GIST, gastrointestinal stromal tumors; PDA, pancreatic ductal adenocarcinoma; EAC, esophageal adenocarcinoma; BBB, blood-brain barrier; ORR, overall response rate; PFS, progression-free survival; mPFS, median progression-free survival; TTP, time to progression; DCR, disease control rate; $\mathrm{CBR}$, clinical benefit rate; DLT, dose-limiting toxicity; MTD, maximum tolerated dose; RP2D, recommended phase II dose; ADRs, adverse reactions; $\mathrm{SD}$, stable disease; $\mathrm{PR}$, partial response; $\mathrm{CR}$, complete response; $\mathrm{CI}$, confidence interval; $\mathrm{HR}$, hazard ratio. proliferation and represent a key mechanism of tumorigenesis (2). The solid tumors for which the CCND-CDK4/6-INK4$\mathrm{Rb}$ pathway is more frequently deregulated through direct genetic, epigenetic or transcriptional modifications are breast, head and neck, lung, pancreatic, ovarian and bladder cancer, melanoma, endometrial carcinoma, liposarcoma, neuroblastoma, and malignant rabdoid tumors (3-25). Because of their central role in tumorigenesis and progression, CDK4 and 6 might represent a valid therapeutic target for cancer treatment in a broad spectrum of solid tumors.

\section{CDK 4/6 INHIBITORS: AN OVERVIEW}

\section{Mechanism of Action and Toxicities}

After the discovery of CDK 4/6 role in tumorigenesis, several CDK inhibitors have been developed for clinical use. The most recent are selective for CDK4 and CDK6, preventing inhibition of other CDKs activity (1). Three CDK4/6i are currently approved in clinical practice, namely: palbociclib, ribociclib, and abemaciclib. Their mechanism of action is based on the binding to $\mathrm{CDK} 4$ and 6 ATP pocket, which leads to a substantial inactivation of CCND-CDK4/6 complexes, with a subsequent increase in the activity of pRb. The logic consequence is a G1 phase arrest (Figure 2). The interference with cell cycle progression results in an increased apoptosis phenomena in tumor cells $(1,2)$.

Palbociclib and ribociclib are similar in chemical structure, while abemaciclib differs and has a higher CDK4/6 binding power than the other two CDK4/6i. More specifically, abemaciclib shows higher selectivity for the complex CDK4/cyclin D1 compared to the other two compounds, and is 14 times more potent against CDK4 than CDK6 $(2,26)$. Cell cycle arrest and subsequent apoptosis are sought to be the most relevant mechanism of action of CDK4/6i. However, a very recent study based on mouse models of breast cancer and other solid tumors and on a confirmatory trascriptomic analysis of serial biopsies from a clinical trial involving CDK4/6i in breast cancer, showed that CDK4/6 inhibition might also induce a broad spectrum of immunologic events. More precisely, they seem to increase the antigen presenting capability of tumor cells, while concurrently reducing the immunosuppressive population of $\mathrm{T}$ regulator lymphocytes. This could in turn enhance the activation of cytotoxic $\mathrm{T}$ cells, which ultimately kill tumor cells (27). However, immunologic effects of CDK4/6i are still object of debate and need further validation/confirmation. Despite a very similar mechanism of action, dose limiting toxicities (DLTs) observed in phase I trials differed, with neutropenia being the DLT for palbociclib, diarrhea and fatigue for abemaciclib, and neutropenia, mucositis, asymptomatic thrombocytopenia, pulmonary embolism, increased creatinine, hyponatriemia, and QTcF prolongation for ribociclib $(2,28)$. Some of the latter toxicities (such as creatinine increase or thromboembolic events) were also reported for abemaciclib however they did not represent formal DLTs in phase I trials. The most common CDK4/6i toxicities of any grade observed in pivotal phase III trials were neutropenia, leukopenia, fatigue and 


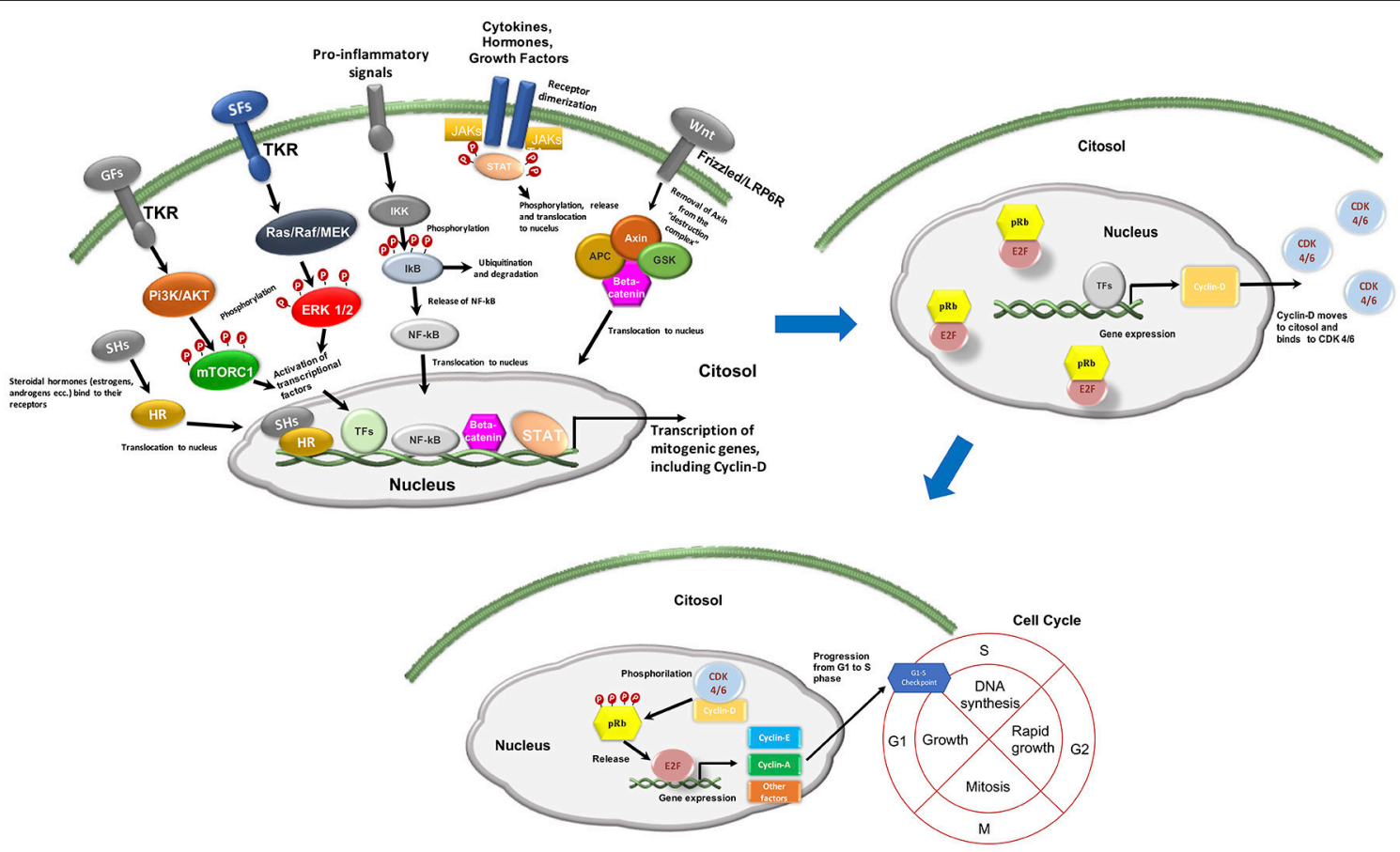

FIGURE 1 | Mitogenic signaling and cell cycle progression. GFs, growth factors; TKR, tyrosine kinase receptor; SFs, survival factors; HR, hormone receptor; SHs, steroidal hormones (i.e., estrogens, androgens); TFs, transcriptional factors.

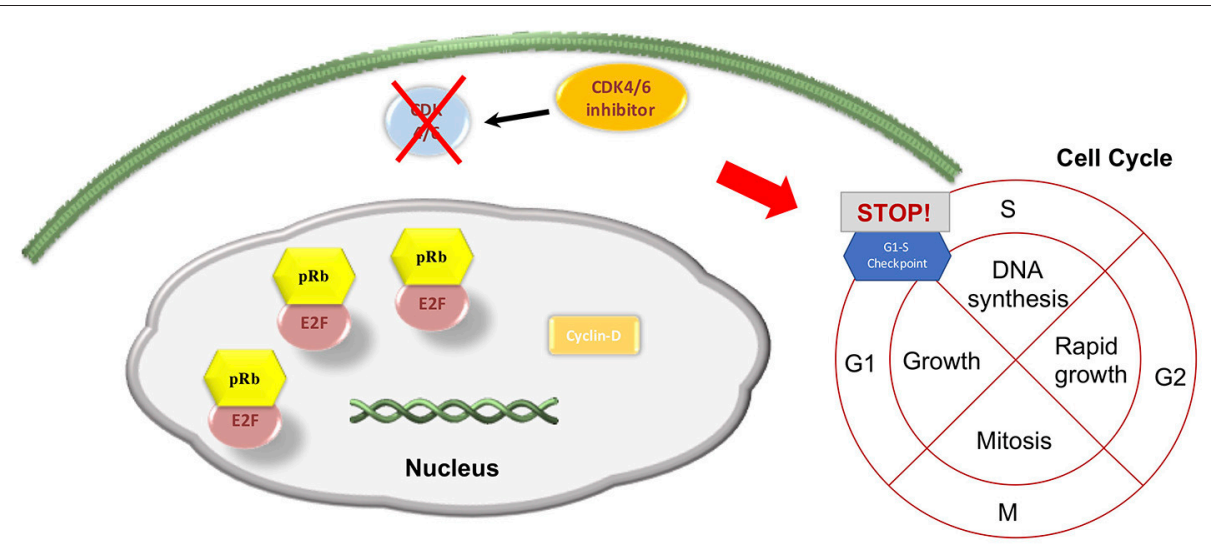

FIGURE 2 | CDK4/6 inhibitors' main effect on cell cycle progression.

nausea for palbociclib $(29,30)$, neutropenia, nausea, infections, fatigue and diarrhea for ribociclib $(31,32)$, creatinine increase, diarrhea, fatigue, and neutropenia for abemaciclib $(33,34)$. The pathophysiology of such toxicities has mostly to be linked to CDK4/6i mechanism of action. Additionally, abemaciclib-induced creatinine increase, might be due to its competitive inhibition of efflux transporters of creatinine (26). A comparison between main pharmacokinetic and pharmacodynamic properties among the three molecules is reported in Table 1. All of the three molecules are orally administered and are metabolized by the liver. Palbociclib and ribociclib, due to longer half-life than abemaciclib, can be administered once daily, while abemaciclib needs twice daily administration.

\section{Current Indications}

The three inhibitors are currently available for the treatment of hormone receptor positive $(\mathrm{HR}+)$ Human Epidermal Growth Factor Receptor 2 negative (HER2-) MBC in combination with an aromatase inhibitor (AI) as first-line endocrine therapy or in combination with fulvestrant in pretreated patients. All of these combinations substantially doubled the comparator in terms of median progression-free survival (PFS) (29-34). Moreover, ribociclib was also studied in combination with tamoxifen or AIs 
TABLE 1 | CDK 4/6 inhibitors' pharmacological characteristics.

\begin{tabular}{|c|c|c|c|}
\hline \multirow{2}{*}{$\begin{array}{l}\text { Drug } \\
\text { properties }\end{array}$} & \multicolumn{3}{|c|}{ CDK 4/6 inhibitors } \\
\hline & Palbociclib & Ribociclib & Abemaciclib \\
\hline Bioavailability (35) & $46 \%$ & Unknown & $45 \%$ \\
\hline $\begin{array}{l}\text { Protein binding } \\
\text { (35) }\end{array}$ & $85 \%$ & $\sim 70 \%$ & $96.3 \%$ \\
\hline Metabolism (35) & Liver & Liver & Liver \\
\hline $\begin{array}{l}\text { Elimination half-life } \\
\text { (35) }\end{array}$ & $29( \pm 5) h$ & $32.0(29.7-54.7) \mathrm{h}$ & $18.3 \mathrm{~h}$ \\
\hline Excretion (35) & $\begin{array}{l}74 \% \text { feces, } 18 \% \\
\text { urine }\end{array}$ & $\begin{array}{l}69 \% \text { feces, } 23 \% \\
\text { urine }\end{array}$ & $\begin{array}{l}81 \% \text { feces, } \\
3 \% \text { urine }\end{array}$ \\
\hline \multicolumn{4}{|l|}{ IC50 (nM) (2) } \\
\hline > CDK4-cyclin D1 & 11 & 10 & 2 \\
\hline $\begin{array}{l}\text { - CDK6-cyclin } \\
\text { D1-2-3 }\end{array}$ & 15 & 39 & 10 \\
\hline > CDK1-cyclin B & $>10,000$ & 113,000 & 1,627 \\
\hline $\begin{array}{l}\text { - CDK2-cyclin } \\
\text { A-E }\end{array}$ & $>10,000$ & 76,000 & 504 \\
\hline > CDK9-cyclin T & NR & NR & 57 \\
\hline MTDs (2) & $125 \mathrm{mg}$ & $900 \mathrm{mg}$ & $\begin{array}{l}200 \mathrm{mg} \text { every } \\
12 \mathrm{~h}\end{array}$ \\
\hline DLTs (2) & Neutropenia & $\begin{array}{l}\text { Neutropenia, } \\
\text { Mucositis, } \\
\text { Asymptomatic } \\
\text { thrombocytopenia, } \\
\text { Pulmonary } \\
\text { embolism, } \\
\text { Increased } \\
\text { creatinine, } \\
\text { Hyponatriemia, } \\
\text { QTcF prolongation } \\
\text { (>500 ms) }\end{array}$ & Fatigue \\
\hline $\begin{array}{l}\text { Recommended } \\
\text { dose (35) }\end{array}$ & $\begin{array}{l}125 \text { mg/die on a } \\
21 \text {-on-28-days } \\
\text { schedule }\end{array}$ & $\begin{array}{l}600 \text { mg/die on a } \\
21 \text {-on-28-days } \\
\text { schedule }\end{array}$ & $\begin{array}{l}200 \text { mg twice } \\
\text { daily }\end{array}$ \\
\hline Administration (35) & Oral & Oral & Oral \\
\hline
\end{tabular}

and a GnRH analog (GnRHa) in pre-/perimenopausal setting in the context of the MONALEESA 7 phase III trial (36), which enrolled HR+ HER2- MBC in first line setting and results were in line with those published in the other CDK4/6i pivotal trials. Results and characteristics of the pivotal trials, namely PALOMA 2 and 3, MONALEESA 2, 3, and 7, and MONARCH 2 and 3 are reported in Table 2 .

\section{SINGLE AGENTS CDK4/6I: CURRENT EVIDENCE}

As previously reported, the CCND-CDK4/6-INK4-Rb pathway is frequently deregulated through direct genetic, epigenetic or transcriptional modifications in a broad variety of neoplasms (325). Indeed, apart from their use in combination with ET for the treatment of HR+ HER2- MBC, CDK4/6i are also under study as single agent in breast cancer (BC) and other solid tumors. The following paragraphs will resume the current preclinical and clinical evidence supporting this experimental treatment strategy.

\section{Preclinical Evidence}

Single agent CDK4/6i have shown consistent activity in preclinical models (38-56). In brief, the most relevant results were observed in in vivo and/or in vitro models of colon cancer (palbociclib, abemaciclib), glioblastoma (palbociclib, abemaciclib), breast cancer (palbociclib, ribociclib, abemaciclib), prostate carcinoma (palbociclib), sarcomas (palbociclib and ribociclib), pancreatic ductal adenocarcinoma (palbociclib), melanoma (palbociclib, ribociclib, abemaciclib), non-small cell lung cancer (palbociclib, abemaciclib), and esophageal adenocarcinoma (abemaciclib).

\section{Palbociclib}

A study demonstrated a potent antitumor activity in different mice models, bearing colon cancer, glioblastoma, breast, and prostate carcinoma xenografts. Palbociclib, given as continuous treatment, was able to arrest growth and induce regression of tumor xenografts. A modest activity was also observed in non-small cell lung cancer (NSCLC) models (38). Palbociclib was also able to arrest the growth of estrogen receptor-positive $(\mathrm{ER}+)$ BC cell lines (39). A potent antitumor activity was also demonstrated in an ex vivo model of human breast tumors (40). Palbociclib activity was demonstrated on cell lines and intracranial xenografts of glioblastoma multiforme (GBM) (41). In the latter case, the proneural subtype appeared to be the most sensitive to palbociclib activity (42). In ovarian cancer cell lines, Palbociclib induces G0/G1 cell cycle arrest by reducing $\mathrm{pRb}$ phosphorylation (43). Palbociclib is also effective in arresting cell cycle progression and blocking proliferation in synovial sarcomas cell lines (44). Another study demonstrated that palbociclib may inhibit cellular growth and induce senescence in liposarcoma cell lines and mice xenografts (45) and in sarcoma cell lines (46). An antiproliferative effect was observed also in rhabdomyosarcoma-derived cell cultures (47). Palbociclib was also studied in immunocompromised mice with subcutaneous and intrasplenic injections of pancreatic ductal adenocarcinoma (PDA) cell lines derived from patients' specimens. The CDK 4/6i significantly disrupted extracellular matrix organization and increased quiescence and apoptosis, decreased invasion, metastatic spread and tumor progression (48).

\section{Ribociclib}

Ribociclib as single agent is effective in inhibiting cell growth in liposarcoma cell lines. Moreover, the administration to mice bearing human liposarcoma xenografts resulted in tumor growth inhibition and/or tumor regression. A similar effect was noted in preclinical models of breast cancers with intact estrogen receptor and/or activating aberrations of PIK3CA/HER2 (49). In preclinical models, ribociclib also showed some activity in melanomas with activating mutations of BRAF or NRAS (50).

\section{Abemaciclib}

Abemaciclib is effective in inducing cell cycle arrest and tumor growth inhibition in colon cancer and breast cancer cell lines and in mice bearing human melanoma and colon cancer xenografts $(51,52)$. Abemaciclib, similarly to temozolamide, increased survival in a rat xenograft model of glioblastoma 
TABLE 2 | Characteristics of pivotal trials concerning CDK4/6 inhibitors approved for clinical practice.

\begin{tabular}{|c|c|c|c|c|c|c|c|}
\hline \multirow[t]{2}{*}{ Characteristics } & \multicolumn{7}{|c|}{ Pivotal trials } \\
\hline & Paloma 2 (29) & Paloma 3 (30) & Monaleesa 2 (31) & Monaleesa 7 (36) & Monaleesa 3 (32) & Monarch-3 (33) & Monarch-2 (34) \\
\hline Combination & $\begin{array}{l}\text { Palbociclib + } \\
\text { letrozole vs. } \\
\text { letrozole }\end{array}$ & $\begin{array}{l}\text { Palbociclib + } \\
\text { fulvestrant vs. } \\
\text { fulvestrant }\end{array}$ & $\begin{array}{l}\text { Ribociclib + } \\
\text { letrozole vs. } \\
\text { letrozole }\end{array}$ & $\begin{array}{l}\text { Ribociclib + } \\
\text { tamoxifen or Al + } \\
\text { GnRHa vs. } \\
\text { tamoxifen or Al + } \\
\text { GnRHa }\end{array}$ & $\begin{array}{l}\text { Ribociclib + } \\
\text { fulvestrant vs. } \\
\text { fulvestrant }\end{array}$ & $\begin{array}{l}\text { Abemaciclib + } \\
\text { NSAI vs. NSAI }\end{array}$ & $\begin{array}{l}\text { Abemaciclib + } \\
\text { fulvestrant vs. } \\
\text { fulvestrant }\end{array}$ \\
\hline $\begin{array}{l}\text { Menopausal } \\
\text { status }\end{array}$ & $\begin{array}{l}\text { Post-menopausal } \\
\text { (iatrogenic or } \\
\text { physiologic) }\end{array}$ & $\begin{array}{l}\text { Post-menopausal } \\
\text { (iatrogenic or } \\
\text { physiologic) }\end{array}$ & Post-menopausal & $\begin{array}{l}\text { Pre- and } \\
\text { perimenopausal }\end{array}$ & Post-menopausal & $\begin{array}{l}\text { Post-menopausal } \\
\text { (iatrogenic or } \\
\text { physiologic) }\end{array}$ & $\begin{array}{l}\text { Post-menopausal } \\
\text { (iatrogenic or } \\
\text { physiologic) }\end{array}$ \\
\hline Setting & $\begin{array}{l}\text { 1st line HR+ } \\
\text { HER2- MBC }\end{array}$ & $\begin{array}{l}\geq 1 \text { st line HR+ } \\
\text { HER2- MBC }\end{array}$ & $\begin{array}{l}\text { 1st line HR+ } \\
\text { HER2- MBC }\end{array}$ & $\begin{array}{l}\text { 1st line HR+ } \\
\text { HER2- MBC }\end{array}$ & $\begin{array}{l}\geq 1 \text { st line HR+ } \\
\text { HER2- MBC }\end{array}$ & $\begin{array}{l}\text { 1st line HR+ } \\
\text { HER2- MBC }\end{array}$ & $\begin{array}{l}\text { 1st line HR+ } \\
\text { HER2- MBC }\end{array}$ \\
\hline $\begin{array}{l}\text { Median PFS } \\
\text { (months) }\end{array}$ & 24.8 vs. 14.5 & 9.5 vs. 4.6 & NR vs. 14.7 & 23.8 vs. 13.0 & 20.5 vs. 12.8 & NR vs. 14.7 & 16.4 vs. 9.3 \\
\hline $\begin{array}{l}\text { PFS HR (95\% } \\
\text { Cis); } p \text {-value* }\end{array}$ & $\begin{array}{l}0.58(0.46-0.72) \\
p<0.001\end{array}$ & $\begin{array}{l}0.46(0.36-0.59) \\
p<0.0001\end{array}$ & $\begin{array}{l}0.56(0.43-0.72) \\
p=3.29 \times 10^{-6}\end{array}$ & $\begin{array}{l}0.553 \\
(0.441-0.694) \\
p<0.0001\end{array}$ & $\begin{array}{l}0.59(0.48-0.73) \\
p=4.10 \times 10^{-7}\end{array}$ & $\begin{array}{l}0.543 \\
(0.409-0.723) ; \\
p=0.000021\end{array}$ & $\begin{array}{l}0.553 \\
(0.449-0.681) \\
p=0.000021\end{array}$ \\
\hline ORR & 42.1 vs. $34.7 \%$ & 25 vs. $11 \%$ & 40.7 vs. $27.5 \%$ & 51 vs. $36 \%$ & 41 vs. $9 \%$ & 59.2 vs. $43.8 \%$ & 48.1 vs. $21.3 \%$ \\
\hline Trial phase & III & III & III & III & III & III & III \\
\hline $\begin{array}{l}\text { FDA/EMA } \\
\text { status }\end{array}$ & $\mathrm{A} / \mathrm{A}$ & $\mathrm{A} / \mathrm{A}$ & $\mathrm{A} / \mathrm{A}$ & $\mathrm{A} / \mathrm{NA}$ & $\mathrm{A} / \mathrm{NA}$ & $\mathrm{A} / \mathrm{A}$ & $\mathrm{A} / \mathrm{A}$ \\
\hline
\end{tabular}

*OS data not mature, yet, except for palbociclib + fulvestrant vs. fulvestrant [HR 0.81 (0.64-1.03); p = 0.043] (37).

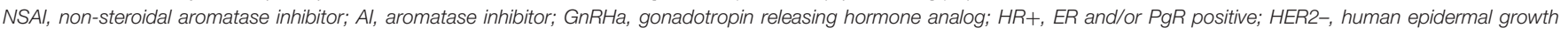
factor receptor 2 negative; $A$, approved; NA, not yet approved.

(53), thus suggesting a significant capability to cross the blood-brain barrier (BBB). It was also effective on NSCLC tumor xenografts (54). Abemaciclib was also able to inhibit growth of melanoma tumor xenografts and delay tumor recurrence in combination with vemurafenib. Furthermore, abemaciclib yielded tumor growth regression in a vemurafenibresistant model, and induced apoptotic cell death in a concentration-dependent manner, suggesting that this drug might be a viable therapeutic option to overcome MAPKmediated resistance to B-RAF inhibitors in B-RAF V600E melanoma (55). Abemaciclib was also evaluated in preclinical models of esophageal adenocarcinoma (EAC): in tumor cell lines it appeared to increased apoptosis and decrease proliferation while in mice models, it was able to decrease of more than $20 \%$ tumor volume (56).

\section{Clinical Evidence}

The preclinical data reviewed above offered a solid rationale to test single agent CDK4/6i in clinical trials.

\section{Palbociclib: Completed Trials}

Palbociclib was tested in a cohort of 41 patients affected by several solid tumors in the context of a phase I dose escalating study. Tumors had been screened for the presence of $\mathrm{pRb}$. In this trial the maximum tolerated dose (MTD) and recommended phase II dose (RP2D) of single-agent palbociclib was $125 \mathrm{mg} /$ day on a 21-of-28 days schedule. The most frequent G3/4 toxicities were neutropenia, leucopenia and anemia with the first present in $20 \%$ of cases, the second in $10 \%$ and the latter in $7 \%$ of cases. Albeit being a phase I trial, clinical activity was also reported. Among 37 evaluable patients, $27 \%$ achieved stable disease (SD) for at least 4 cycles and $16 \%$ for at least 10 cycles (57).

Several phase II studies tested palbociclib monotherapy in a broad variety of solid tumors, namely well-differentiated or dedifferentiated liposarcoma (WD/DDLS) $(58,59)$, NSCLC (60), gastric and esophageal cancer (61), urothelial carcinoma (62), epithelial ovarian cancer (63), HR+ and triple negative (TN) BC $(64,65)$. The best results were observed in WD/DDLS, ovarian and $\mathrm{BC}$, counterbalanced by overall disappointing results in the other neoplasms. The most frequent grade (G)3/4 adverse reactions (ADRs) were hematologic.

More in details, a phase II study explored the activity and safety of palbociclib on a $200 \mathrm{mg} /$ day on a 14-of-21-days schedule in patients with advanced CDK4-amplified WD/DDLS. The trial enrolled 30 patients. The estimated 12-weeks PFS rate was $66 \%$, far exceeding the expected rate of $40 \%$ for an active agent. There was only one partial response (PR) and 19 SD at 12 weeks. Median PFS (mPFS) was 17.9 weeks. The most frequent G3/4 ADRs were neutropenia (50\%), leukopenia (47\%), thrombocytopenia (30\%), lymphopenia (27\%), and anemia (17\%) (58). In a subsequent study, patients affected by advanced WD/DDLS were treated with standard palbociclib $125 \mathrm{mg}$ for 21 days in 28 days-schedule. The trial results showed a successful PFS at 12 weeks of 57.2\% [95\% Confidence Interval (CI): 42.468.8\%]. The median PFS was 17.9 weeks (95\% CI: $11.9-24.0$ weeks). One complete response (CR) was observed. G3/4 ADRs were primarily hematologic and included neutropenia (33\%), without neutropenic fever (59). A clinical trial in previouslytreated patients with recurrent or metastatic NSCLC was prematurely halted due to lack of objective tumor responses. Half 
of evaluable patients achieved SD. The MPFS was 12.5 weeks. One patient experienced G3 transaminitis and unexpected G4 rhabdomyolysis, supposedly due to concomitant use of highdose simvastatin. Some patients developed G3 or 4 neutropenia, and G3 thrombocytopenia (60). Single agent palbociclib was also not effective in advanced gastric and esophageal tumors, even if the patients had been selected for Rb expression and despite 19/38 tumors showed amplification of CCND1. The median duration of treatment was of 1.7 months, with a maximum of 5.5 months. No objective responses were observed (61). Similarly, palbociclib was not effective in a phase II trial conducted in patients affected by metastatic urothelial carcinoma with both p16 loss and pRb expression (62). A single arm phase II trial in patients with heavily pretreated epithelial ovarian cancer showed a discreet activity and efficacy for palbociclib as single agent. Thirty percent of patients were progression-free at 6 months, with a median PFS of 3.7 months (95\% CI: 1.2-6.2). A $4 \%$ of PR and a $65 \%$ of SD were observed. The toxicity was minimal. Predictive biomarker analyses are ongoing (63). A phase II study of palbociclib as single agent was conducted in patients with metastatic $\mathrm{pRb}$ positive $\mathrm{BC}$. The clinical benefit rate (CBR) at 6 months, composed of all complete responses (CR), PR and SD observed as best responses, was $21 \%$, the median PFS were of 4.1 months (95\% CI 2.3-7.7) for patients with ER+ HER2- BC, 18.8 months (95\% CI: 5.1-NE) for ER+ HER2+ patients and 1.8 months (95\% CI: $0.9-\mathrm{NE}$ ) for patients with triple negative (TN) tumors, respectively. Neutropenia (50\%) and thrombocytopenia (21\%) were the most frequent G3/4 toxicities (64). The TREND study, an Italian multicentre open-label phase II trial, compared single agent palbociclib with palbociclib combined with the same ET received prior to disease progression in post-menopausal women with HR+ HER2- MBC. The trial enrolled 115 patients, the primary endpoint was CBR. In both arms, $67 \%$ of pts had the study treatment as second line, $33 \%$ as third line, and about $1 / 3$ of pts also had received 1 prior chemotherapy for MBC. The CBR was similar in both arms, $54 \%$ (95\% CI: $42-67 \%)$ observed in the combination one, and 60\% (95\% CI: $48-73 \%)$ with palbociclib alone. The Overall Response Rates (ORR), composed of all CR and PR observed as best responses, were 11\% (95\% CI: 3$19 \%)$ and $7 \%$ (95\% CI: $0.4-13 \%)$ with the combination therapy and palbociclib alone, respectively. The trial was not powered to estimate survival endpoints, however exploratory analyses were performed, with no significant differences observed in PFS $(p=0.13)$ and a longer median duration of clinical benefit for the combination than for the single agent [11.5 months, 95\% CI: 8.6-17.8 vs. 6 months, 95\% CI: 3.9-9.9; Hazard Ratio (HR): 0.31, 95\% CI: $0.1-0.7$, p-value 0.001]. Overall, however, the primary endpoint did not differ significantly between the 2 study arms, thereby lending support to the potential use of palbociclib as single agent in pretreated patients with HR+ HER2- MBC (65).

\section{Palbociclib: Ongoing Trials}

A number of trials are currently ongoing with single agent palbociclib in several advanced solid tumors.

Results are awaited from the NCT03219554 single arm phase II trial that is evaluating the efficacy of single agent palbociclib in patients with recurrent or metastatic advanced thymic epithelial tumors pretreated with one or more cytotoxic chemotherapy. The primary endpoint is PFS (66). The activity and efficacy of single agent palbociclib will be also evaluated in the Lung-MAP trial, a phase II/III biomarker-driven study for second line therapy of squamous cell lung cancer (SCLC). More specifically, single agent palbociclib will be studied in the context of a sub-study that includes all patients that harbored genetic alterations involving cell-cycle genes. The accrual has been completed and results are awaited (67). A phase II study, the NCT01907607-CYCLIGIST, has also already completed accrual and will evaluate the efficacy of single agent palbociclib in patients with gastrointestinal stromal tumors (GIST) refractory to imatinib and sunitinib. The primary endpoint is the nonprogression rate at 4 months (68). Results are also awaited for the NCT01356628. This multicenter single arm phase II trial is exploring the efficacy of single agent palbociclib in advanced hepatocellular carcinoma pretreated with standard therapies. The primary endpoint is the time to disease progression (TTP) (69). Another phase II trial, the NCT02806648-PALBONET, is ongoing to demonstrate the safety and activity of palbociclib in subject affected by pNET with overexpression of CDK4, RB1, and CCND1. Results are awaited (70).

Several trials are currently recruiting participants. The NCT02530320 phase II study is ongoing in patients with oligodendroglioma or recurrent anaplastic oligoastrocytoma with preserved $\mathrm{pRb}$ activity. The primary end point is the PFS rate at 6 months (71). Another ongoing single arm phase II study (NCT03242382) will evaluate the efficacy of secondline palbociclib in patients with advanced soft tissue sarcomas with CDK4 overexpression. The primary endpoint is the PFS at 6 months (72). The NCT01037790 phase II clinical trial is studying activity, safety and tolerability of single agent palbociclib in preatreated refractory solid tumors, including metastatic colorectal cancer that harbors the Kras or BRAF mutation, metastatic breast cancer, advanced or metastatic esophageal and/or gastric cancer, cisplatin-refractory, unresectable germ cell tumors and any tumor type if tissue tests positive for CCND1 amplification, CDK4/6 mutation, CCND2 amplification or any other functional alteration at the G1/S checkpoint. Co-primary endpoints are the response rates and the safety and tolerability profile. The trial is currently recruiting participants (73).

Finally, a single arm phase II trial (NCT03454919) in acral melanoma bearing alterations in cell cycle pathways, including CDK4 amplification and/or CCND1 amplification and/or P16 (CDKN2A) loss, is going to start but not yet recruiting patients. The primary end point is PFS (74).

\section{Ribociclib: Completed and Ongoing Trials}

The initial phase I dose escalation study of single-agent ribociclib enrolled 128 patients with $\mathrm{pRb}$ positive advanced solid tumors and lymphomas. The MTD and RP2D were established as 900 and $600 \mathrm{mg} /$ day, respectively, on a 21-of-28-days schedule. The most relevant G3/4 ADRs were neutropenia (27\%), leukopenia (17\%), fatigue (2\%), and nausea (2\%). An asymptomatic QTcF prolongation was observable, but mostly with doses $\geq 600 \mathrm{mg} /$ day ( $9 \%$ of patients at $600 \mathrm{mg} /$ day; $33 \%$ at doses $>600 \mathrm{mg} /$ day). Response rates were evaluable for 110 patients, though this was 
a phase I trial. There were $3 \mathrm{PR}$ and $43 \mathrm{SD}$ as best response; eight patients were progression-free for more than 6 months (75). Results are awaited for an ongoing phase I study (NCT02345824) that will assess tumor pharmacokinetics and efficacy of ribociclib in patients with recurrent glioblastoma or anaplastic glioma (76).

Several phase II trials of single agent ribociclib are currently ongoing. More specifically, the NCT02571829 trial is assessing the efficacy and safety of ribociclib in patients with advanced WD/DDLS. Patients' recruitment has been completed (77). Another trial is ongoing in patients with advanced neuroendocrine tumors of foregut origin progressed after prior systemic therapy. The primary endpoint is the objective response rate (78). The NCT02300987 randomized study is ongoing in patients with relapsed, refractory, incurable teratoma with recent progression from at least 1 prior line of chemotherapy and for which no additional standard surgical or medical therapy exists. This trial will compare ribociclib to placebo. The primary endpoint is PFS. Recruitment has been completed and results are awaited (79). Another phase II single arm study (NCT03096912) assessing efficacy and safety of ribociclib in patients with advanced WD/DDLS is currently recruiting patients. The primary endpoint is the response to therapy after 36 months, as evaluated by RECIST and Choi criteria (80).

\section{Abemaciclib: Completed Trials}

Abemaciclib as single agent was investigated in a multicentre phase I study conducted by Patnaik and colleagues. In this study, the 225 enrolled patients were affected by NSCLC, BC, melanoma, colorectal cancer and GBM. The MTD was $200 \mathrm{mg}$ twice daily and the DLT was G3 fatigue. The most relevant G3 ADRs were diarrhea (5\%), nausea (4\%), fatigue (7\%), vomiting (2\%), and neutropenia (7\%). Activity data were also reported. Fifteen patients experienced SD for at least 4 cycles, with 3 patients achieving SD for 8,16 , and 26 cycles, respectively. One patient with ovarian cancer had a durable and relevant CA125 response. One patient with KRAS mutant NSCLC had a PR. One patient with NRAS mutant melanoma had a confirmed PR. The ORR was $31 \%$ for HR+ BC. Moreover, when also considering patients who achieved SD as a best response, $61 \%$ of the overall subjects obtained a clinical response lasting at least 6 months $(81,82)$. A focus on 49 NSCLC patients was also published. The most relevant G3 ADRs were diarrhea (2\%), nausea (4\%), fatigue $(2 \%)$, vomiting $(2 \%)$, and anemia (2\%); there were no G4 events. Activity results were also shown. The disease control rate $(\mathrm{DCR}=\mathrm{CR}+\mathrm{PR}+\mathrm{SD})$ was $51 \%$ with 1 confirmed $\mathrm{PR}$. The median duration of SD was 5.6 months and the median PFS was 2.1 months. Twenty patients reached at least 4 cycles and 13 reached at least 6 cycles. Among those 49 patients, 19 were affected by KRAS wildtype tumors, 26 by KRAS mutant tumors and 4 with unknown KRAS status. The DCR was $37 \%$ for KRAS wildtype and 54\% for KRAS mutant NSCLC, consistently with what observed in xenograft studies. The MTD was $200 \mathrm{mg}$ twice daily (83). A randomized phase III study JUNIPER, has compared abemaciclib plus best supportive care to erlotinib plus best supportive care in patients with metastatic NSCLC with a detectable KRAS mutation who have progressed after platinumbased chemotherapy. The primary endpoint was OS and the study failed to show a significant benefit. Moreover, researchers reported a higher-than-expected OS rate in the control group based on historical data $(84,85)$.

At present, the most relevant trial involving abemaciclib in monotherapy is the MONARCH-1. Such study was a single arm phase II trial in which the efficacy and safety profile of abemaciclib as a single agent were investigated in HR+ HER2MBC. The 132 enrolled patients had to be progressed on or after prior ET and must have received at least two prior chemotherapy regimens, at least one but no more than two in the metastatic setting. Abemaciclib was administrated at the dose of $200 \mathrm{mg}$ every $12 \mathrm{~h}$ on a continuous schedule. The ORR (primary endpoint) was $19.7 \%$ (95\% CI, 13.3-27.5), the CBR was $42.4 \%$, mPFS was 6 months (95\% CI 4.2-7.5) and median overall survival (OS) was 17.7 months (95\% CI, 16 to not reached). In this study the most common ADRs were diarrhea, fatigue, nausea, neutropenia, leukopenia, anemia and increased serum creatinine (86). This trial led to the FDA approval of abemaciclib as single therapy in pretreated patients with HR+ HER2- MBC.

Finally, preliminary results from a Simon 2-stage single arm phase II trial in patients affected by HR+ HER2- MBC, NSCLC or melanoma with brain metastases showed a number of brain partial responses that met the predefined threshold for expanding the trial to stage 2 . For each patient cerebrospinal fluid concentration of unbound abemaciclib were comparable and consistent with those in the plasma and tumor tissue (87). This trial provided evidence that abemaciclib is able to cross the $\mathrm{BBB}$ in human, coherently with preclinical evidence on mice xenografts (53). The second stage is ongoing.

\section{Abemaciclib: Ongoing Trials}

Several ongoing trials with single agent abemaciclib have completed patients' recruitment. An asian phase I study (NCT02014129) is evaluating the safety and toxicities of abemaciclib in advanced solid tumors and lymphomas in Japanese participants (88). Abemaciclib is also currently investigated in GBM at first relapse in the NCT02981940 phase II trial. Tumors must be $\mathrm{pRb}$ wild type and carry inactivation of $\mathrm{CDKN} 2 \mathrm{~A} / \mathrm{B}$ or $\mathrm{C}$ in the tumor by homozygous deletion. The coprimary endpoint are the intratumoral abemaciclib concentration and the 6-months PFS (89). Another phase II trial (active but no more recruiting), the NCT02450539, is evaluating the efficacy of abemaciclib compared to docetaxel in patients with metastatic squamous NSCLC previously treated with platinum-based chemotherapy. The primary endpoint is PFS (90). A phase II ongoing study (NCT02308020), currently recruiting participants, is evaluating the activity and efficacy of abemaciclib in patients with brain metastases secondary to HR+ breast cancer, NSCLC or melanoma. The primary endpoint is the objective intracranial response rate. Preliminary results have been reported in a previous section of this review (87). Other ongoing trials are currently enrolling participants. More specifically, the NCT02919696 phase I trial is studying abemaciclib in native chinese patients with advanced and/or metastatic cancers (91). A phase II trial (NCT03130439) is also investigating the efficacy and activity of abemaciclib in metastatic triple negative breast cancer expressing $\mathrm{pRb}$. The primary endpoint is the ORR 
TABLE 3 | Currently ongoing trials on CDK 4/6 inhibitors as single agent in solid tumors.

\begin{tabular}{|c|c|c|c|c|}
\hline & CDK4/6 inhibitor & $N$ & Phase and setting & Primary endpoint(s) \\
\hline NCT03123744 & Palbociclib & 200 & $\begin{array}{l}\text { Non-randomized Phase II study of palbociclib in adult subjects with } \\
\text { recurrent or refractory advanced cancers with aberration(s) in cyclin } \\
\text { (CCN/CDK) signaling. }\end{array}$ & $\begin{array}{l}\text { Response rates in subjects with } \\
\text { advanced cancer and aberrations of } \\
\text { cyclin pathway gene(s) who are } \\
\text { treated with palbociclib }\end{array}$ \\
\hline NCT02530320 & Palbociclib & 40 & $\begin{array}{l}\text { Phase II pilot, prospective, open label, multicenter clinical trial, to evaluate } \\
\text { the safety and efficacy of palbociclib, in patients with oligodendroglioma or } \\
\text { recurrent oligoastrocytoma anaplastic with the activity of the protein rb } \\
\text { preserved }\end{array}$ & PFS, PFS6m \\
\hline NCT03454919 & Palbociclib & 60 & $\begin{array}{l}\text { Phase II clinical study on efficacy of palbociclib in advanced acral melanoma } \\
\text { with cell cycle gene aberrations }\end{array}$ & $\begin{array}{l}\text { ORR, Complete response and partial } \\
\text { response }\end{array}$ \\
\hline NCT 03242382 & Palbociclib & 38 & $\begin{array}{l}\text { Phase II multicenter trial of palbociclib in second line of advanced sarcomas } \\
\text { with CDK4 overexpression. }\end{array}$ & PFS rate \\
\hline NCT03219554 & Palbociclib & 33 & $\begin{array}{l}\text { Phase II single center, open-label, single arm study of palbociclib treatment } \\
\text { in patients with recurrent or metastatic advanced thymic epithelial tumor } \\
\text { (TET) after failure of one or more cytotoxic chemotherapy regimens }\end{array}$ & PFS \\
\hline NCT01907607 & Palbociclib & 63 & $\begin{array}{l}\text { Multicentre single-arm phase II study evaluating the efficacy and safety of } \\
\text { orally Palbociclib, } 125 \mathrm{mg} / \text { day, } 21 \text { days on/7 days off, in patients with } \\
\text { documented disease progression while on therapy with second line sunitinib } \\
\text { for unresectable and/or metastatic GIST. }\end{array}$ & $\begin{array}{l}\text { Efficacy, assessed based on } \\
\text { 4-months non-progression }\end{array}$ \\
\hline NCT01356628 & Palbociclib & 23 & $\begin{array}{l}\text { Phase II study of Palbociclib in the treatment of patients with advanced } \\
\text { hepatocellular carcinoma (HCC), a type of adenocarcinoma and the most } \\
\text { common type of liver tumor. }\end{array}$ & Time to disease progression \\
\hline NCT02806648 & Palbociclib & 21 & $\begin{array}{l}\text { Phase II trial to assess the activity and safety of Palbociclib in patients with } \\
\text { well and moderately differentiated metastatic pancreatic neuroendocrine } \\
\text { tumors (pNET) }\end{array}$ & Response rates \\
\hline NCT01037790 & Palbociclib & 205 & $\begin{array}{l}\text { Phase II trial is studying the side effects and how well PD } 0332991 \text { works in } \\
\text { treating patients with refractory solid tumors. }\end{array}$ & Response rates \\
\hline NCT02345824 & Ribociclib & 3 & $\begin{array}{l}\text { Early-phase study to assess tumor pharmacokinetics and efficacy of the } \\
\text { cdk } 4 / 6 \text { inhibitor Ribociclib in patients with recurrent glioblastoma or } \\
\text { anaplastic glioma }\end{array}$ & $\begin{array}{l}\text { Inhibition of CDK4/CDK6 signaling } \\
\text { pathway in cell proliferation }\end{array}$ \\
\hline NCT03096912 & Ribociclib & 30 & $\begin{array}{l}\text { Phase II single arm study assessing efficacy and safety of Ribociclib in } \\
\text { patients with advanced well-differentiated or dedifferentiated liposarcoma }\end{array}$ & $\begin{array}{l}\text { Response to therapy as evaluated by } \\
\text { RECIST } 1.1 \\
\text { Response to therapy as evaluated by } \\
\text { Choi [Time Frame: } 36 \text { months] }\end{array}$ \\
\hline NCT02571829 & Ribociclib & 30 & $\begin{array}{l}\text { Phase II single arm study assessing efficacy and safety of Ribociclib in } \\
\text { patients with advanced well-differentiated or dedifferentiated liposarcoma }\end{array}$ & $\begin{array}{l}\text { Response to therapy as evaluated by } \\
\text { RECIST } 1.1 \text { and Choi [Time Frame: } \\
36 \text { months ( } 24 \text { months accrual period } \\
\text { and } 12 \text { months follow up period)] }\end{array}$ \\
\hline NCT02300987 & Ribociclib & 10 & $\begin{array}{l}\text { Randomized, blinded, placebo-controlled, phase II trial of LEE011 in } \\
\text { patients with relapsed, refractory, incurable teratoma with recent } \\
\text { progression. }\end{array}$ & $\begin{array}{l}\text { Progression free survival (PFS) [Time } \\
\text { Frame: at } 4 \text { months] }\end{array}$ \\
\hline NCT02919696 & Abemaciclib & 20 & $\begin{array}{l}\text { Phase I study of Abemaciclib in native Chinese patients with advanced } \\
\text { and/or metastatic cancers. }\end{array}$ & $\begin{array}{l}\text { Number of Participants with One or } \\
\text { More Drug Related Adverse Events } \\
\text { Number of participants with one or } \\
\text { more drug related adverse events }\end{array}$ \\
\hline NCT02014129 & Abemaciclib & 12 & Phase I study of Abemaciclib in Japanese patients with advanced cancer & $\begin{array}{l}\text { Number of Participants with } \\
\text { LY2835219 Dose-Limiting Toxicities } \\
\text { (DLT) }\end{array}$ \\
\hline NCT02981940 & Abemaciclib & 36 & Phase II study of Abemaciclib in recurrent glioblastoma & $\begin{array}{l}\text { Intratumoral abemaciclib } \\
\text { concentration [Time Frame: } 2 \text { years] } \\
\text { PFS6m }\end{array}$ \\
\hline NCT03130439 & Abemaciclib & 37 & $\begin{array}{l}\text { Phase II study of Abemaciclib for patients with retinoblastoma-positive, } \\
\text { triple negative metastatic breast cancer. }\end{array}$ & $\begin{array}{l}\text { Objective Response Rate [Time } \\
\text { Frame: } 2 \text { years] } \\
\text { ORR as confirmed Complete } \\
\text { Response (CR) or Partial Response } \\
\text { (PR) per Response Evaluation Criteria } \\
\text { in Solid Tumors (RECIST) }\end{array}$ \\
\hline NCT02846987 & Abemaciclib & 30 & Phase II study of Abemaciclib in dedifferentiated liposarcoma & PFS [Time Frame: 12 weeks] \\
\hline NCT03356587 & Abemaciclib & 32 & $\begin{array}{l}\text { Biomarker-driven, open label, single arm, multicentre phase II study of } \\
\text { Abemaciclib in patients with recurrent or metastatic head and neck } \\
\text { squamous cell carcinoma who failed to platinum-based therapy }\end{array}$ & $\begin{array}{l}\text { Response rate [Time Frame: } 24 \\
\text { months] }\end{array}$ \\
\hline
\end{tabular}


TABLE 3 | Continued

\begin{tabular}{|c|c|c|c|c|}
\hline & CDK4/6 inhibitor & $\boldsymbol{N}$ & Phase and setting & Primary endpoint(s) \\
\hline NCT03356223 & Abemaciclib & 25 & $\begin{array}{l}\text { Phase II trial aiming to evaluate the clinical interest of Abemaciclib } \\
\text { monotherapy in patients with locally advanced/metastatic head and neck } \\
\text { cancer after failure of platinum and Cetuximab or anti-EGFR-based therapy } \\
\text { and harboring an homozygous deletion of cdkn2a, and/or an amplification } \\
\text { of CCND1 and/or of CDK6 }\end{array}$ & $\begin{array}{l}\text { The } 8 \text {-weeks non-progression rate } \\
\text { defined as the rate of patients with } \\
\text { complete response }(\mathrm{CR}) \text {, partial } \\
\text { response (PR) or stable disease (SD) } \\
\text { lasting at least } 8 \text { weeks, according to } \\
\text { RECIST v1.1 [Time Frame: } 8 \text { weeks } \\
\text { after start of treatment] }\end{array}$ \\
\hline NCT02450539 & Abemaciclib & 150 & $\begin{array}{l}\text { Randomized phase II study of Abemaciclib vs. docetaxel in patients with } \\
\text { stage iv squamous non-small cell lung cancer previously treated with } \\
\text { platinum-based chemotherapy. }\end{array}$ & PFS \\
\hline NCT02308020 & Abemaciclib & 247 & $\begin{array}{l}\text { Phase } 2 \text { study of Abemaciclib in patients with brain metastases secondary } \\
\text { to hormone receptor positive breast cancer, non-small cell lung cancer, or } \\
\text { melanoma. }\end{array}$ & $\begin{array}{l}\text { Percentage of Participants Achieving } \\
\text { Complete Response (CR) or Partial } \\
\text { Response (PR): Objective Intracranial } \\
\text { Response Rate (OIRR) }\end{array}$ \\
\hline NCT03310879 & Abemaciclib & 38 & $\begin{array}{l}\text { Phase II study of the cdk4/6 inhibitor Abemaciclib in patients with solid } \\
\text { tumors harboring genetic alterations in genes encoding D-type cyclins or } \\
\text { amplification of CDK4 or } 6 \text {. }\end{array}$ & Progression-free rate \\
\hline
\end{tabular}

(92). The NCT02846987 phase II trial is currently recruiting patients affected by not surgically resectable locally advanced or recurrent dedifferentiated liposarcoma with any number of prior therapies (including none). The primary endpoint is PFS (93). A biomarker-driven phase II study (NCT03356587) of abemaciclib in patients with recurrent or metastatic head and neck squamous cell carcinoma who failed to platinum-based therapy is also currently recruiting participants. Primary endpoint is response rate (94). Another phase II trial in (NCT03356223) patients with locally advanced/metastatic head and neck cancer is currently evaluating abemaciclib monotherapy after failure of platinum and cetuximab or anti-EGFR-based therapy, but only in tumors harboring a homozygous deletion of CDKN2A, and/or amplification of CCND1 and/or of CDK6. The primary endpoint is the 8-weeks non-progression rate (95). Finally, the NCT03310879 phase II study is testing abemaciclib in patients with solid tumors of non-breast origin harboring genetic alterations in genes encoding D-type Cyclins or amplification of CDK4/6 without therapeutic alternative. The progression-free rate at 4 months is the primary endpoint (96).

Ongoing trials for palbociclib, ribociclib, and abemaciclib are resumed in Table 3.

\section{CONCLUSIONS}

Albeit it is unquestionable, at present, that CDK 4/6i treatment proved to be more efficacious in combination strategies (e.g., in $\mathrm{HR}+\mathrm{HER} 2-\mathrm{MBC}$ is in combination with endocrine agents), the MONARCH 1 trial results (86) led to the FDA approval of abemaciclib as monotherapy for the treatment of adult patients with $\mathrm{HR}+\mathrm{HER} 2-\mathrm{MBC}$ with disease progression after prior ET and CT received in metastatic setting. This study opened up a new scenario for CDK4/6i, making them suitable as single agent treatment in heavily pretreated MBC.
In this perspective, the TREND trial provided some evidence for some activity of palbociclib as single agent in pretreated patients with HR+HER2- MBC (65). A cross-trial comparison of response rate from the MONARCH-1 and TREND trial suggests that abemaciclib might be more effective than palbociclib in the same disease setting. However, this hint should be taken as hypothesis only, given the lack of direct comparisons between the two CDK4/6i. Additionally, there is a strong need for biomarkers predictive of response and resistance to better define which patients could benefit most from these drugs. In fact, mechanisms of resistance to CDK4/6i therapy have yet to be clearly identified. Laboratory evidences suggest that markers of intrinsic resistance might be the $\mathrm{pRb}$ loss and subsequent increase in $\mathrm{p} 16^{\mathrm{INK} 4 \mathrm{~A}}$, deregulation of cyclin E expression, E2F family members amplification and TP53 mutations (97). Interestingly, a study recently published from Condorelli et al. showed for the first time in human patients that acquired mutations leading to functional loss of $\mathrm{pRb}$ encoding gene (RB1) might emerge under treatment with palbociclib and ribociclib, maybe due to selective pressure from the CDK4/6i and might potentially confer therapeutic resistance (98). Results from ongoing trials in solid tumors will surely shed a light on CDK4/6i future development as single agents. It is likely that eventual new treatment indications might be acquired by the three inhibitors in the next future, especially in tumors where few therapeutic options are available, such as sarcomas.

\section{AUTHOR CONTRIBUTIONS}

All authors conceived the review. FS, ID, CR, and PD performed the literature search. FS drew the figures. FS, ID, and LD wrote the first draft of the manuscript. All authors revised and approved the final version of the manuscript. 


\section{REFERENCES}

1. Musgrove EA, Caldon CE, Barraclough J, Stone A, Sutherland RL. Cyclin D as a therapeutic target in cancer. Nat Rev Cancer (2011) 45:558-72. doi: 10.1038/nrc3090

2. Hamilton E, Infante JR. Targeting CDK4/6 in patients with cancer. Cancer Treat Rev. (2016) 45:129-38. doi: 10.1016/j.ctrv.2016.03.002

3. Cassier P, Trédan O, Seigne C, Lavergne E, Fayette J, Desseigne F, et al. Identifying actionable targets in advanced cancer patients: preliminary results from the Profiler program. J Clin Oncol. (2014) 32(5_Suppl.):2621. doi: $10.1200 /$ jco.2014.32.15_suppl.2621

4. Cancer Genome Atlas Network. Comprehensive molecular portraits of human breast tumors. Nature (2012) 490:61-70. doi: 10.1038/nature11412

5. Geradts J, Wilson PA. High frequency of aberrant p16(INK4A) expression in human breast cancer. Am J Pathol. (1996) 149:15-20.

6. Lim JT, Mansukhani M, Weinstein IB. Cyclin-dependent kinase 6 associates with the androgen receptor and enhances its transcriptional activity in prostate cancer cells. Proc Natl Acad Sci USA. (2005) 102:5156-61. doi: $10.1073 /$ pnas.0501203102

7. Young RJ, Waldeck K, Martin C, Foo JH, Cameron DP, Kirby L, et al. Loss of CDKN2A expression is a frequent event in primary invasive melanoma and correlates with sensitivity to the CDK4/6 inhibitor PD0332991 in melanoma cell lines. Pigment Cell Melanoma Res. (2014) 27:590-600. doi: $10.1111 / \mathrm{pcmr} .12228$

8. Reed AL, Califano J, Cairns P, Westra WH, Jones RM, Koch W, et al. High frequency of p16 (CDKN2/MTS-1/INK4A) inactivation in head and neck squamous cell carcinoma. Cancer Res. (1996) 56:3630-3.

9. Molenaar JJ, Ebus ME, Koster J, van Sluis P, van Noesel CJ, Versteeg R, et al. Cyclin D1 and CDK4 activity contribute to the undifferentiated phenotype in neuroblastoma. Cancer Res. (2008) 68:2599-609. doi: 10.1158/0008-5472.CAN-07-5032

10. Crago AM, Singer S. Clinical and molecular approaches to well differentiated and dedifferentiated liposarcoma. Curr Opin Oncol. (2011) 23:373-8. doi: 10.1097/CCO.0b013e32834796e6

11. Singer S, Socci ND, Ambrosini G, Sambol E, Decarolis P, Wu Y, et al. Gene expression profiling of liposarcoma identifies distinct biological types/subtypes and potential therapeutic targets in well-differentiated and dedifferentiated liposarcoma. Cancer Res. (2007) 67:6626-36. doi: 10.1158/0008-5472.CAN-07-0584

12. Louis-Brennetot C, Coindre JM, Ferreira C, Pérot G, Terrier P, Aurias A. The CDKN2A/CDKN2B/CDK4/CCND1 pathway is pivotal in well-differentiated and dedifferentiated liposarcoma oncogenesis: an analysis of 104 tumors. Genes Chromosomes Cancer (2011) 50:896-907. doi: 10.1002/gcc.20909

13. Zuo L, Weger J, Yang Q, Goldstein AM, Tucker MA, Walker GJ, et al. Germline mutations in the p16INK4a binding domain of CDK4 in familial melanoma. Nat Genet. (1996) 12:97-9. doi: 10.1038/ng0196-97

14. Hodis E, Watson IR, Kryukov GV, Arold ST, Imielinski M, Theurillat JP, et al. A landscape of driver mutations in melanoma. Cell (2012) 150:251-63. doi: 10.1016/j.cell.2012.06.024

15. Haluska FG, Hodi FS. Molecular genetics of familial cutaneous melanoma. $J$ Clin Oncol. (1998) 16:670-82. doi: 10.1200/JCO.1998.16.2.670

16. Potrony M, Puig-Butillé JA, Aguilera P, Badenas C, Carrera C, Malvehy J, et al. Increased prevalence of lung, breast, and pancreatic cancers in addition to melanoma risk in families bearing the cyclin-dependent kinase inhibitor 2A mutation: Implications for genetic counseling. J Am Acad Dermatol. (2014) 71:888-95. doi: 10.1016/j.jaad.2014.06.036

17. Dreyling M, Kluin-Nelemans HC, Beà S, Hartmann E, Salaverria I, Hutter $\mathrm{G}$, et al. Update on the molecular pathogenesis and clinical treatment of mantle cell lymphoma: report of the 10th annual conference of the European Mantle Cell Lymphoma Network. Leuk Lymphoma (2011) 52:222636. doi: 10.3109/10428194.2011.600488

18. Pérez-Galán P, Dreyling M, Wiestner A. Mantle cell lymphoma: biology, pathogenesis, and the molecular basis of treatment in the genomic era. Blood (2011) 117:26-38. doi: 10.1182/blood-2010-04-189977

19. Fernandez V, Hartmann E, Ott G, Campo E, Rosenwald A. Pathogenesis of mantle-cell lymphoma: all oncogenic roads lead to dysregulation of cell cycle and DNA damage response pathways. J Clin Oncol. (2005) 23:6364-9. doi: 10.1200/JCO.2005.05.019
20. Abou-Zeid AA, Azzam AZ, Kamel NA. Methylation status of the gene promoter of cyclin-dependent kinase inhibitor 2A (CDKN2A) in ovarian cancer. Scand J Clin Lab Invest. (2011) 71:542-7. doi: 10.3109/00365513.2011.590224

21. Jackson EM, Sievert AJ, Gai X, Hakonarson H, Judkins AR, Tooke L, et al. Genomic analysis using high-density single nucleotide polymorphismbased oligonucleotide arrays and multiplex ligation-dependent probe amplification provides a comprehensive analysis of INI1/SMARCB1 in malignant rhabdoid tumors. Clin Cancer Res. (2009) 15:1923-30. doi: 10.1158/1078-0432.CCR-08-2091

22. Kuwahara Y, Charboneau A, Knudsen ES, Weissman BE. Reexpression of hSNF5 in malignant rhabdoid tumor cell lines causes cell cycle arrest through a p21 (CIP1/WAF1)-dependent mechanism. Cancer Res. (2010) 70:1854-65. doi: 10.1158/0008-5472.CAN-09-1922

23. Zhang ZK, Davies KP, Allen J, Zhu L, Pestell RG, Zagzag D, et al. Cell cycle arrest and repression of cyclin D1 transcription by INI1/hSNF5. Mol Cell Biol. (2002) 22:5975-88. doi: 10.1128/MCB.22.16.5975-5988.2002

24. Wang X, Wu J, Lin Y, Zhu Y, Xu X, Xu X, et al. MicroRNA-320c inhibits tumorous behaviors of bladder cancer by targeting Cyclin-dependent kinase 6. J Exp Clin Cancer Res. (2014) 33:69. doi: 10.1186/s13046-0140069-6

25. Lin Y, Wu J, Chen H, Mao Y, Liu Y, Mao Q, et al. Cyclin-dependent kinase 4 is a novel target in micoRNA-195-mediated cell cycle arrest in bladder cancer cells. FEBS Lett. (2012) 586:442-7. doi: 10.1016/j.febslet.2012.01.027

26. Corona SP, Generali D. Abemaciclib: a CDK4/6 inhibitor for the treatment of HR+/HeR2- advanced breast cancer. Drug Design Dev Ther. (2018) 12:32130. doi: 10.2147/DDDT.S137783

27. Goel S, DeCristo MJ, Watt AC, BrinJones H, Sceneay J, Li BB, et al. CDK4/6 inhibition triggers anti-tumor immunity. Nature (2017) 548:471-5. doi: $10.1038 /$ nature23465

28. Knudsen ES, Hutcheson J, Vail P, Witkiewicz AK. Biological specificity of CDK4/6 inhibitors: dose response relationship, in vivo signaling, and composite response signature. Oncotarget (2017) 8:43678-91. doi: 10.18632/oncotarget.18435

29. Finn RS, Martin M, Rugo HS, Jones S, Im SA, Gelmon K, et al. Palbociclib and letrozole in advanced breast cancer. N Engl J Med. (2016) 375:1925-36. doi: 10.1056/NEJMoa1607303

30. Cristofanilli M, Turner NC, Bondarenko I, Ro J, Im SA, Masuda N, et al. Fulvestrant plus palbociclib versus fulvestrant plus placebo for treatment of hormone-receptor-positive, HER2-negative metastatic breast cancer that progressed on previous endocrine therapy (PALOMA-3): final analysis of the multicentre, double-blind, phase 3 randomised controlled trial. Lancet Oncol. (2016) 17:425-39. doi: 10.1016/S1470-2045(15)00613-0

31. Hortobagyi GN, Stemmer SM, Burris HA, Yap YS, Sonke GS, Paluch-Shimon $\mathrm{S}$, et al. Ribociclib as first-line therapy for HR-positive, advanced breast cancer. N Engl J Med. (2016) 375:1738-48. doi: 10.1056/NEJMoa1609709

32. Slamon DJ, Neven P, Chia S, Fasching PA, De Laurentiis M, Im SA, et al. Phase III randomized study of ribociclib and fulvestrant in hormone receptor-positive, human epidermal growth factor receptor 2-negative advanced breast cancer: MONALEESA-3. J Clin Oncol. (2018) 36:2465-72. doi: 10.1200/JCO.2018.78.9909

33. Goetz MP, Toi M, Campone M, Sohn J, Paluch-Shimon S, Huober J, et al. MONARCH 3: abemaciclib as initial therapy for advanced breast cancer. J Clin Oncol. (2017) 35:3638-46. doi: 10.1200/JCO.2017.75.6155

34. Sledge GW Jr., Toi M, Neven P, Sohn J, Inoue K, Pivot X, et al. MONARCH 2: abemaciclib in combination with fulvestrant in women with HR+/HER2advanced breast cancer who had progressed while receiving endocrine therapy. J Clin Oncol. (2017) 35:2875-84. doi: 10.1200/JCO.2017.73.7585

35. Prescription Drug Information, Interactions \& Side Effects (2018). Available online at: https://www.drugs.com

36. Tripathy D, Im SA, Colleoni M, Franke F, Bardia A, Harbeck N, et al. Ribociclib plus endocrine therapy for premenopausal women with hormone-receptor-positive, advanced breast cancer (MONALEESA7): a randomized phase 3 trial. Lancet Oncol. (2018) 19:904-15. doi: 10.1016/S1470-2045(18)30292-4

37. Turner NC, Slamon DJ, Ro J, Bondarenko I, Im SA, Masuda N, et al. Overall survival with palbociclib and fulvestrant in advanced breast cancer. $N$ Engl J Med. (2018). doi: 10.1056/NEJMoa1810527 
38. Fry DW, Harvey PJ, Keller PR, Elliott WL, Meade M, Trachet E, et al. Specific inhibition of cyclin-dependent kinase 4/6 by PD 0332991 and associated antitumor activity in human tumor xenografts. Mol Cancer Ther. (2004) 3:1427-38.

39. Finn RS, Dering J, Conklin D, Kalous O, Cohen DJ, Desai AJ, et al. PD 0332991, a selective cyclin D kinase $4 / 6$ inhibitor, preferentially inhibits proliferation of luminal estrogen receptor-positive human breast cancer cell lines in vitro. Breast Cancer Res. (2009) 11:R77. doi: 10.1186/bcr2419

40. Dean JL, McClendon AK, Hickey TE, Butler LM, Tilley WD, Witkiewicz $\mathrm{AK}$, et al. Therapeutic response to CDK4/6 inhibition in breast cancer defined by ex vivo analyses of human tumors. Cell Cycle (2012) 11:2756-61. doi: $10.4161 /$ cc. 21195

41. Michaud K, Solomon DA, Oermann E, Kim JS, Zhong WZ, Prados MD, et al. Pharmacologic inhibition of cyclin-dependent kinases 4 and 6 arrests the growth of glioblastoma multiforme intracranial xenografts. Cancer Res. (2010) 70:3228-38. doi: 10.1158/0008-5472.CAN-09-4559

42. Wiedemeyer WR, Dunn IF, Quayle SN, Zhang J, Chheda MG, Dunn GP, et al. Pattern of retinoblastoma pathway inactivation dictates response to CDK4/6 inhibition in GBM. Proc Natl Acad Sci USA. (2010) 107:11501-6. doi: 10.1073/pnas.1001613107

43. Konecny GE, Winterhoff B, Kolarova T, Qi J, Manivong K, Dering J, et al. Expression of p16 and retinoblastoma deter- mines response to CDK4/6 inhibition in ovarian cancer. Clin Cancer Res. (2011) 17:1591-602. doi: 10.1158/1078-0432.CCR-10-2307

44. Vlenterie M, Hillebrandt-Roeffen MH, Schaars EW, Flucke UE, Fleuren ED, Navis AC, et al. Targeting cyclin-dependent kinases in synovial sarcoma: palbociclib as a potential treatment for synovial sarcoma patients. Ann Surg Oncol. (2016) 23:2745-52. doi: 10.1245/s10434-016-5341-x

45. Barretina J, Taylor BS, Banerji S, Ramos AH, Lagos-Quintana M, Decarolis PL, et al. Subtype-specific genomic alterations define new targets for soft-tissue sarcoma therapy. Nat Genet. (2010) 42:715-21. doi: 10.1038/ng.619

46. Perez M, Muñoz-Galván S, Jiménez-García MP, Marín JJ, Carnero A. Efficacy of CDK4 inhibition against sarcomas depends on their levels of CDK4 and pl6ink4 mRNA. Oncotarget (2015) 6:40557-74. doi: 10.18632/oncotarget.5829

47. Saab R, Bills JL, Miceli AP, Anderson CM, Khoury JD, Fry DW, et al. Pharmacologic inhibition of cyclin-dependent kinase 4/6 activity arrests proliferation in myoblasts and rhabdomyosarcoma-derived cells. Mol Cancer Ther. (2006) 5:1299-308. doi: 10.1158/1535-7163.MCT-05-0383

48. Chou A, Froio D, Nagrial AM, Parkin A, Murphy KJ, Chin VT, et al. Tailored first-line and second-line CDK4-targeting treatment combinations in mouse models of pancreatic cancer. Gut (2018) 67:2142-55. doi: 10.1136/gutjnl-2017-315144

49. Zhang YX, Sicinska E, Czaplinski JT, Remillard SP, Moss S, Wang Y, et al. Antiproliferative effects of CDK4/6 inhibition in CDK4-amplified human liposarcoma in vitro and in vivo. Mol Cancer Ther. (2014) 13:2184-93. doi: 10.1158/1535-7163.MCT-14-0387

50. Kim S, et al. LEE011: an orally bioavailable, selective small molecule inhibitor of CDK4/6-reactivating Rb in cancer. Mol Cancer Ther. (2014) 12(11_Supplement):PR02. doi: 10.1158/1535-7163.TARG-13-PR02

51. Tate SC, Cai S, Ajamie RT, Burke T, Beckmann RP, Chan EM, et al. Semi mechanistic pharmacokinetic/pharmacodynamic modeling of the antitumor activity of LY2835219, a new cyclin-dependent kinase 4/6 inhibitor, in mice bearing human tumor xenografts. Clin Cancer Res. (2014) 20:3763-74. doi: 10.1158/1078-0432.CCR-13-2846

52. Gelbert LM, Cai S, Lin X, Sanchez-Martinez C, Del Prado M, Lallena MJ, et al. Preclinical characterization of the CDK4/6 inhibitor LY2835219: in-vivo cell cycle-dependent/independent anti-tumor activities alone/in combination with gemcitabine. Invest New Drugs (2014) 32:825-37. doi: 10.1007/s10637-014-0120-7

53. Raub TJ, Wishart GN, Kulanthaivel P, Staton BA, Ajamie RT, Sawada GA, et al. Brain exposure of two selective dual CDK4 and CDK6 inhibitors and the antitumor activity of CDK4 and 6 inhibition in combination with temozolomide in an intracranial glioblastoma xenograft. Drug Metab Dispos. (2015) 43:9:1360-71. doi: 10.1124/dmd.114.062745

54. Dempsey JA, Chan EM, Burke TF, Beckmann RP. LY2835219, a selective inhibitor of CDK4 and CDK6, inhibits growth in preclinical models of human cancer. Cancer Res. (2013) 73(8_Suppl.):LB-122. doi: 10.1158/1538-7445.AM2013-LB-122

55. Yadav V, Burke TF, Huber L, Van Horn RD, Zhang Y, Buchanan SG, et al. The CDK4/6 inhibitor LY2835219 overcomes vemurafenib resistance resulting from MAPK reactivation and cyclin D1 upregulation. Mol Cancer Ther. (2014) 13:2253-63. doi: 10.1158/1535-7163.MCT-14-0257

56. Kosovec JE, Zaidi AH, Omstead AN, Matsui D, Biedka MJ, Cox EJ, et al. CDK4/6 dual inhibitor abemaciclib demonstrates compelling preclinical activity against esophageal adenocarcinoma: a novel therapeutic option for a deadly disease. Oncotarget (2017) 8:100421-32. doi: 10.18632/oncotarget.22244

57. Flaherty KT, Lorusso PM, Demichele A, Abramson VG, Courtney R, Randolph SS, et al. Phase I, dose-escalation trial of the oral cyclin-dependent kinase 4/6 inhibitor PD 0332991, administered using a 21-day schedule in patients with advanced cancer. Clin Cancer Res. (2012) 18:568-76. doi: 10.1158/1078-0432.CCR-11-0509

58. Dickson MA, Tap WD, Keohan ML, D’Angelo SP, Gounder MM, Antonescu CR, et al. Phase II trial of the CDK4 inhibitor PD0332991 in patients with advanced CDK4-amplified well-differentiated or dedifferentiated liposarcoma. J Clin Oncol. (2013) 31:2024-8. doi: 10.1200/JCO.2012.46.5476

59. Dickson MA, Schwartz GK, Keohan ML, D'Angelo SP, Gounder MM, Chi P, et al. Progression-free survival among patients with welldifferentiated or dedifferentiated liposarcoma treated with CDK4 inhibitor palbociclib: a phase II clinical trial. JAMA Oncol. (2016) 2:937-40. doi: 10.1001/jamaoncol.2016.0264

60. Gopalan PK, Pinder MC, Chiappori A, Ivey AM, Villegas AG, Kaye FJ, et al. A phase II clinical trial of the CDK $4 / 6$ inhibitor palbociclib (PD 0332991) in previously treated, advanced non-small cell lung cancer (NSCLC) patients with inactivated CDKN2A. J Clin Oncol. (2014) 32(5_Suppl.):8077. doi: 10.1200/jco.2014.32.15_suppl.8077

61. Karasic TB, O’Hara MH, Teitelbaum UR, Damjanov N, Giantonio BJ, d'Entremont TS, et al. Phase II trial of palbociclib in patients with advanced esophageal or gastric cancer. J Clin Oncol. (2018) 36(4_Suppl.):68. doi: 10.1200/JCO.2018.36.4_suppl.68

62. US National Library of Medicine. ClinicalTrials.gov (2018). Available online at: https://clinicaltrials.gov/ct2/show/NCT02334527?term=palbociclib\& draw $=2 \&$ rank $=16$

63. Konecny GE, Hendrickson AEW, Jatoi A, Burton JK, Paroly J, Glaspy JA, et al. A multicenter open-label phase II study of the efficacy and safety of palbociclib a cyclin-dependent kinases 4 and 6 inhibitor in patients with recurrent ovarian cancer. J Clin Oncol. (2016) 34(15_Suppl.):5557. doi: 10.1200/JCO.2016.34.15_suppl.5557

64. DeMichele A, Clark AS, Tan KS, Heitjan DF, Gramlich K, Gallagher $\mathrm{M}$, et al. A phase II trial of an oral CDK 4/6 inhibitor, PD0332991, in advanced breast cancer. J Clin Oncol. (2013) 31(15_Suppl.):519. doi: 10.1200/jco.2013.31.15_suppl.519

65. Malorni L, Curigliano G, Minisini AM, Cinieri S, Tondini CA, D’Hollander K, et al. Palbociclib as single agent or in combination with the endocrine therapy received before disease progression for estrogen receptor-positive, HER2negative metastatic breast cancer: TREnd trial. Ann Oncol. (2018) 29:1748-54. doi: 10.1093/annonc/mdy214

66. US National Library of Medicine. ClinicalTrials.gov (2018). Available online at: https://clinicaltrials.gov/ct2/show/NCT03219554?term=palbociclib\& draw $=7 \&$ rank $=65$

67. Steuer CE, Papadimitrakopoulou V, Herbst RS, Redman MW, Hirsch FR, Mack PC, et al. Innovative clinical trials: the LUNG-MAP study. Clin Pharmacol Ther. (2015) 97:488-91. doi: 10.1002/cpt.88

68. US National Library of Medicine. ClinicalTrials.gov (2018). Available online at: https://clinicaltrials.gov/ct2/show/NCT01907607

69. US National Library of Medicine. ClinicalTrials.gov (2018). Available online at: https://clinicaltrials.gov/ct2/show/NCT01356628?term=palbociclib\& draw $=11$ \&rank $=101$

70. US National Library of Medicine. ClinicalTrials.gov (2018). Available online at: https://clinicaltrials.gov/ct2/show/NCT02806648

71. US National Library of Medicine. ClinicalTrials.gov (2018). Available online at: https://clinicaltrials.gov/ct2/show/NCT02530320?term=palbociclib\& rank $=8$ 
72. US National Library of Medicine. ClinicalTrials.gov (2018). Available online at: https://clinicaltrials.gov/ct2/show/NCT03242382?term=palbociclib\& draw $=4 \&$ rank $=37$

73. US National Library of Medicine. ClinicalTrials.gov (2018). Available online at: https://clinicaltrials.gov/ct2/show/NCT01037790?term=palbociclib\& draw $=15$ \&rank $=145$

74. US National Library of Medicine. ClinicalTrials.gov (2018). Available online at: https://clinicaltrials.gov/ct2/show/NCT03454919?term=palbociclib\& draw $=2 \&$ rank $=12$

75. Infante JR, Cassier PA, Gerecitano JF, Witteveen PO, Chugh R, Ribrag V, et al. A phase I study of the cyclin-dependent kinase $4 / 6$ inhibitor ribociclib (LEE011) in patients with advanced solid tumors and lymphomas. Clin Cancer Res. (2016) 22:5696-705. doi: 10.1158/1078-0432.CCR-16-1248

76. US National Library of Medicine. ClinicalTrials.gov (2018). Available online at: https://clinicaltrials.gov/ct2/show/NCT02345824?term=ribociclib\&draw= $2 \&$ rank $=4$

77. US National Library of Medicine. ClinicalTrials.gov (2018). Available online at: https://clinicaltrials.gov/ct2/show/NCT02571829?term=ribociclib\&draw= 3\&rank $=12$

78. US National Library of Medicine. ClinicalTrials.gov (2018). Available online at: https:/clinicaltrials.gov/ct2/show/NCT02420691?term=ribociclib\&draw= 5\&rank=32

79. US National Library of Medicine. ClinicalTrials.gov (2018). Available online at: https:/clinicaltrials.gov/ct2/show/NCT02300987?term=ribociclib\&draw= $7 \&$ rank $=60$

80. US National Library of Medicine. ClinicalTrials.gov (2018). Available online at: https://clinicaltrials.gov/ct2/show/NCT03096912?term=ribociclib\&draw= 2\&rank=2

81. Patnaik A, Rosen LS, Tolaney SM, Tolcher AW, Goldman JW, Gandhi L, et al. Efficacy and safety of abemaciclib, an inhibitor of CDK4 and CDK6, for patients with breast cancer, non-small cell lung cancer, and other solid tumors. Cancer Discov. (2016) 6:740-53. doi: 10.1158/2159-8290.CD-16-0095

82. Shapiro G, Rosen LS, Tolcher AW, Goldman JW, Gandhi L, Papadopoulos KP, et al. A first-in-human phase I study of the CDK4/6 inhibitor, LY2835219, for patients with advanced cancer. J Clin Oncol. (2013) 31(15_Suppl.):2500. doi: 10.1200/jco.2013.31.15_suppl.2500

83. Goldman JW, Gandhi L, Patnaik A, Rosen LS, Hilton JF, Papadopoulos KP, et al. Clinical activity of LY2835219, a novel cell cycle inhibitor selective for CDK4 and CDK6, in patients with non-small cell lung cancer. J Clin Oncol. (2014) 32(15_Suppl.):8026. doi: 10.1200/jco.2014.32.15_suppl.8026

84. The ASCO Post. Results From the Phase III JUNIPER Trial Evaluating Abemaciclib in KRAS-Mutated, Advanced NSCLC. The ASCO Post (2017). Available online at: http://www.ascopost.com/News/58135

85. US National Library of Medicine. ClinicalTrials.gov (2018). Available online at: https://clinicaltrials.gov/ct2/show/NCT02152631?term=Abemaciclib\& draw $=3 \&$ rank $=19$

86. Dickler MN, Tolaney SM, Rugo HS, Cortés J, Diéras V, Patt D, et al. MONARCH 1, a phase II study of abemaciclib, a CDK4 and CDK6 inhibitor, as a single agent, in patients with refractory $\operatorname{HR}(+) / \operatorname{HER} 2(-)$ metastatic breast cancer. Clin Cancer Res. (2017) 23:5218-24. doi: 10.1158/1078-0432.CCR-17-0754
87. Tolaney SM, Lin NU, Thornton D, Klise S, Costigan TM, Turner PK, et al. Abemaciclib for the treatment of brain metastases (BM) secondary to hormone receptor positive (HR+), HER2 negative breast cancer. J Clin Oncol. (2017) 35:1019. doi: 10.1200/JCO.2017.35.15_suppl.1019

88. US National Library of Medicine. ClinicalTrials.gov (2018). Available online at: https://clinicaltrials.gov/ct2/show/NCT02014129?term=abemaciclib\& draw $=3$ \&rank $=42$

89. US National Library of Medicine. ClinicalTrials.gov (2018). Available online at: https://clinicaltrials.gov/ct2/show/NCT02981940?term=Abemaciclib\& draw $=2 \&$ rank $=2$

90. US National Library of Medicine. ClinicalTrials.gov (2018). Available online at: https://clinicaltrials.gov/ct2/show/NCT02450539?term=Abemaciclib\& draw $=3 \&$ rank $=18$

91. US National Library of Medicine. ClinicalTrials.gov (2018). Available online at: https://clinicaltrials.gov/ct2/show/NCT02919696?term=Abemaciclib\& draw $=2 \& \operatorname{rank}=6$

92. US National Library of Medicine. ClinicalTrials.gov (2018). Available online at: https://clinicaltrials.gov/ct2/show/NCT03130439?term=Abemaciclib\& draw $=2 \&$ rank $=4$

93. US National Library of Medicine. ClinicalTrials.gov (2018). Available online at: https://clinicaltrials.gov/ct2/show/NCT02846987?term=Abemaciclib\& draw $=2 \& \operatorname{rank}=5$

94. US National Library of Medicine. ClinicalTrials.gov (2018). Available online at: https://clinicaltrials.gov/ct2/show/NCT03356587?term=Abemaciclib\& draw $=2 \&$ rank $=9$

95. US National Library of Medicine. ClinicalTrials.gov (2018). Available online at: https://clinicaltrials.gov/ct2/show/NCT03356223?term=Abemaciclib\& draw $=3 \&$ rank $=14$

96. US National Library of Medicine. ClinicalTrials.gov (2018). Available online at: https://clinicaltrials.gov/ct2/show/NCT03310879?term=Abemaciclib\& draw $=3 \&$ rank $=13$

97. Condorelli R, Spring L, O'Shaughnessy J, Lacroix L, Bailleux C, Scott $\mathrm{V}$, et al. Polyclonal RB1 mutations and acquired resistance to CDK4/6i in patients with metastatic breast cancer. Ann Oncol. (2017) 0:1-6. doi: 10.1093/annonc/mdx784

98. Knudsen ES, Witkiewicz AK. The strange case of CDK4/6 inhibitors: mechanisms, resistance, and combination strategies. Trends Cancer (2017) 3:39-55. doi: 10.1016/j.trecan.2016.11.006

Conflict of Interest Statement: The authors declare that the research was conducted in the absence of any commercial or financial relationships that could be construed as a potential conflict of interest.

Copyright (c) 2018 Schettini, De Santo, Rea, De Placido, Formisano, Giuliano, Arpino, De Laurentiis, Puglisi, De Placido and Del Mastro. This is an open-access article distributed under the terms of the Creative Commons Attribution License (CC $B Y)$. The use, distribution or reproduction in other forums is permitted, provided the original author(s) and the copyright owner(s) are credited and that the original publication in this journal is cited, in accordance with accepted academic practice. No use, distribution or reproduction is permitted which does not comply with these terms. 